\title{
Using Analytical Techniques and Cole Crop Field Responses to Quantify 2,4-D plus Glyphosate Removal from the Surface of Plastic Mulch
}

\author{
Lavesta C. Hand, Kayla M. Eason, Taylor M. Randell, and \\ Timothy L. Grey \\ Department of Crop and Soil Sciences, University of Georgia, \\ Tifton, GA 31794
}

John S. Richburg

Corteva Agrisciences, Headland, AL 36345

Timothy W. Coolong
Department of Horticulture, University of Georgia, Athens, GA 30602

A. Stanley Culpepper

Department of Crop and Soil Sciences, University of Georgia, Tifton, GA 31794

Additional index words. broccoli, Brassica oleracea var. botrytis, collards, Brassica oleracea var. viridis, herbicide removal, multicrop vegetable production, plastic mulch, preplant herbicide application, plasticulture vegetable production

\begin{abstract}
Planting cole crops and leafy greens in plastic mulch free of summer and winter annual broadleaf weeds is challenging. Because these crops are often grown as a second or third crop on mulch, weeds emerge in previously punched plant holes, tears in plastic, and row middles. Without the ability to use tillage and with limited herbicide options available for weed control, achieving a weed-free planting window is not often feasible. Additional herbicide options are needed, but their interaction with plastic mulch must be understood. Therefore, research has determined the persistence of preplant applications of 2,4-D tank-mixed with glyphosate applied over plastic mulch. Analytical laboratory analyses of plastic samples from field experiments, in conjunction with bioassays using broccoli (Brassica oleracea var. botrytis $\mathbf{L}$.) and collard (Brassica oleracea var. viridis L.), evaluated herbicide dissipation. Analytical studies determined that $0.5 \mathrm{~cm}$ of irrigation after herbicide application and 1 day before planting removed $99 \%$ of $2,4-\mathrm{D}$, and $100 \%$ of glyphosate from the plastic mulch. Waiting an additional 14 days after application and irrigation further reduced the amount of $2,4-\mathrm{D}$ on the plastic mulch $88 \%$ to $95 \%$. For the field bioassay, preplant applications of 2,4-D tank-mixed with glyphosate resulted in $7 \%$ or less visual broccoli or collard injury without influencing crop growth, biomass, early season yield, or total yield as long as the mulch was washed with $0.5 \mathrm{~cm}$ of irrigation before planting. These studies also demonstrated there were no differences between the $1 \times$ and $2 \times$ use rates with respect to all response variables measured. Results suggest that 2,4-D and glyphosate can be effectively removed from the surface of plastic mulch with irrigation or rainfall before planting broccoli and collard.
\end{abstract}

Cole crop [broccoli, cabbage (Brassica oleracea var. oleracea L.), and cauliflower (Brassica oleracea var. botrytis L.)] and leafy green [collards and kale (Brassica oleracea var. sabellica L.)] production in the United States comprised 61,263 ha harvested during 2017, with nearly $22 \%$ of that occurring in the state of Georgia (Coolong, 2017; U.S. Department of Agriculture, 2019). In the Southeast, these crops have wide planting windows ranging from August to October and January to April (Coolong et al., 2016; Coolong, 2017). The vast range of planting dates provide unique challenges for weed control, with the
2001). Controlling emerged weeds before seeding or transplanting can be extremely challenging because few herbicides are registered for use by growers. Preplant burndown herbicides with broad-spectrum postemergence activity are limited to glyphosate and paraquat (Kemble et al., 2019). With widespread glyphosate resistance in Palmer amaranth (Amaranthus palmeri S. Wats), paraquat is the only effective option if applied to small weeds (Chaudhari et al., 2017; Culpepper et al., 2006). Glyphosate and paraquat provide variable and often inadequate control of susceptible annual morningglory, wild radish, and cutleaf evening primrose (Culpepper et al., 2005; Hydrick and Shaw, 1995; Leon et al., 2016). Additionally, other vegetable-producing states, including California and Florida, have noted resistance to paraquat in horseweed (Conyza canadensis L.) (Moretti and Hanson, 2016) and American black nightshade (Solanum americanum Mill.) (Chase et al., 1998). Therefore, further control options are necessary to start the season weed-free and allow for the incorporation of multiple mechanisms of action for resistance management purposes.

Tillage in bareground production systems is effective for controlling these weeds and incorporating residual herbicides (Brainard et al., 2013; Cutulle et al., 2019). However, in Georgia, cole crops and leafy greens are often grown in plastic mulch systems. These systems eliminate the potential for tillage as a weed management tool and can increase weed densities and the species present. Although an effective fumigant system is used when laying plastic mulch, it is generally only effective for the first crop produced, often tomato (Solanum lycopersicum L.) or pepper (Capsicum annuum L.), which are considered high-value crops (Csinos et al., 1997; Culpepper et al., 2017; Eure and Culpepper, 2017; Webster et al., 2001). Cole crops and leafy greens are subsequently grown in the plastic mulch system and are often planted 6 to 24 months after the initial fumigation application and plastic mulch installation (Cutulle et al., 2019). By the time cole crops or leafy greens are planted, weeds emerge and establish not only between the plastic mulched beds (i.e., row middles) but also in holes of the plastic mulch from previous crops or areas of natural degradation of the plastic.

Mixtures of 2,4-D with glyphosate or paraquat could benefit growers if applied before planting cole crops and leafy greens because of its ability to control Palmer amaranth, annual morningglory, wild radish, and cutleaf evening primrose (Chaudhari et al., 2017; Culpepper et al., 2005; Leon et al., 2016). Although new 2,4-D formulations have been improved in regard to off-target movement (Corteva, 2018; Sosnoskie et al., 2015), their interactions with plastic mulch are unknown in terms of sorption and dissipation. Herbicide interaction with plastic mulch is variable and specific to a given herbicide. For example, herbicides have been shown to wash off the plastic mulch with an initial irrigation or rainfall event, partially wash off of plastic mulch over time, or bind to the 
plastic mulch without release (Culpepper et al., 2009; Grey et al., 2009, 2018; Randell et al., 2020). Glyphosate and paraquat are examples of herbicides that can be effectively washed off plastic mulch, whereas other herbicides, such as carfentrazone, bind without release (Culpepper et al., 2009; Grey et al., 2009). Flumioxazin applied over plastic mulch is an example of an herbicide that partially washes off the herbicide over time (Grey et al., 2009) and has caused significant injury and yield reductions for squash (Cucumis melo L.) and tomato (Culpepper et al., 2009). Similarly, halosulfuronmethyl applied over plastic mulch, even after 17 to $19 \mathrm{~cm}$ of rainfall, has been shown to damage squash, broccoli, and cabbage (Grey et al., 2018; Randell et al., 2020).

Another factor (in addition to rainfall or irrigation) to consider when understanding the relationship of a given herbicide and plastic mulch is the time interval between application and planting. When halosulfuron was applied over plastic mulch before crop planting, injury generally increased as applications were made closer to planting for squash, broccoli, and cabbage (Randell et al., 2020). In the case of broccoli and cabbage, halosulfuron removal from plastic mulch was more dependent on time than rainfall, with $52 \%$ to $58 \%$ injury for applications $7 \mathrm{~d}$ before planting (DBP) and $36 \%$ to $37 \%$ injury for applications 14 DBP when similar amounts of rainfall were received for both application timings (Randell et al., 2020). Therefore, some herbicides will require not only rainfall or irrigation for removal from plastic mulch but also time.

Understanding the interaction of 2,4-D with plastic mulch is critical to determining the potential for using this herbicide over plastic mulch for cole crop and leafy green production in these systems. If 2,4-D dissipates from the plastic mulch with rainfall, irrigation, or degradation, then it would offer a significant improvement in preplant herbicide options. Therefore, analytical and bioassay experiments were conducted to quantify variable rates of 2,4-D removal from plastic mulch over time and with irrigation before planting broccoli and collards.

\section{Materials and Methods}

Site selection and trial establishment. An experiment was conducted three times with

Received for publication 8 Jan. 2021. Accepted for publication $21 \mathrm{Feb} .2021$.

Published online 29 April 2021.

We thank Tim Richards and Jenna Vance for their technical contributions. We also acknowledge the dedication of the student workers at the time of these studies.

L.C.H. is a Former Graduate Research Assistant. K.M.E. and T.M.R. are Graduate Research Assistants. T.L.G., T.W.C., and A.S.C. are Professors.

J.S.R. is a Senior Research Scientist.

L.C.H. is the corresponding author. E-mail: camphand@uga.edu.

This is an open access article distributed under the CC BY-NC-ND license (https://creativecommons. org/licenses/by-nc-nd/4.0/). broccoli and collards to evaluate crop tolerance to 2,4-D plus glyphosate applied preplant over plastic mulch at the University of Georgia Ponder Research Farm (lat. $31.30^{\prime} 18^{\circ} \mathrm{N}$, long. $83.39^{\prime} 03^{\circ} \mathrm{W}$ ) near Ty Ty, GA, in Fall 2018 and Fall 2019. Soils consisted of a Tifton loamy sand (fine-loamy, kaolinitic, thermic Plinthic Kandiudults) with $84 \%$ to $90 \%$ sand, $8 \%$ to $10 \%$ silt, $2 \%$ to $6 \%$ clay, and $0.63 \%$ to $0.65 \%$ organic matter with $\mathrm{pH} 6.2$ to 6.6 . During the summer before each autumn experiment, the soil within the study site was tilled to remove all plant debris, fumigants were applied, and plastic mulch was installed. During bed formation, the entire study site was treated with a standard three-way fumigant to maintain the experimental area weed-free and assist in controlling nematodes and soil-borne pathogens (Culpepper et al., 2017). The initial bedder (Hendrix \& Dail, Inc., Greenville, NC) injected 1,3-dichloropropene and chloropicrin (Pic-Chlor 60; TriEst Ag Group, Inc. Greenville, NC) at $197 \mathrm{~L} \cdot \mathrm{ha}^{-1}$ to $20 \mathrm{~cm}$ below the bed top using three evenly spaced injection shanks. This was immediately followed by a combination bed shaper and plastic mulch layer (Kennco Manufacturing, Inc., Ruskin, FL), which injected metam sodium (Vapam HL; AMVAC, Los Angeles, CA) to $10 \mathrm{~cm}$ deep with injection shanks $10 \mathrm{~cm}$ apart at 700 $\mathrm{L} \cdot \mathrm{ha}^{-1}$. Immediately following the injection of metam sodium, drip tape was laid in the center of the raised bed $2.5 \mathrm{~cm}$ below the bed surface, and the entire bed was covered with black-onblack totally impermeable film in 2018 and with black-on-white low-density polyethylene mulch during both 2019 studies (Guardian Agricultural Plastics Corporation, Tampa, FL). The final formed bed consisted of an 81-cmwide bed top that was $20 \mathrm{~cm}$ tall and spaced $183 \mathrm{~cm}$ apart. The purpose of this experiment was to gain knowledge of how herbicides interact with plastic mulch to maintain plastic integrity of a summer crop that was not planted (i.e., no holes were punched). All study areas were maintained weed-free with glyphosate, flumioxazin, and $S$-metolachlor applied between plastic mulched beds at least 1 week before planting, followed by hand-weeding as necessary (Kemble et al., 2019).

The experimental design was a randomized complete block design arranged in an augmented factorial of two application rates, four application timings, and a nontreated control. Treatments used for each study were replicated four times. Herbicides included 2,4-D choline (Embed Extra; Corteva Agriscience, Indianapolis, IN) applied at 1065 and $2130 \mathrm{~g}$ ae/ha (1059 and $2118 \mathrm{ppm} / \mathrm{m}^{2}$ ) tank-mixed with glyphosate (Roundup PowerMax II; Bayer Cropscience, St. Louis, MO) at 1125 and 2250 $\mathrm{g}$ ae/ha $\left(1119\right.$ and $\left.2238 \mathrm{ppm} / \mathrm{m}^{2}\right)$, respectively. Tank mixtures were used to represent expected grower practices of $1 \times$ and $2 \times$ rates. Herbicides were applied over plastic mulch 45,30 , 15 , and $1 \mathrm{DBP}$. The 45 DBP applications were made on 6 Sept. 2018, 8 Sept. 2019, and 14 Sept. 2019. The 30 DBP applications were made on 24 Sept. 2018, 23 Sept. 2019, and 3 Oct. 2019. The 15 DBP applications were made on 12 Oct. 2018, 8 Oct. 2019, and 17
Oct. 2019. The 1 DBP applications were made on 24 Oct. 2018, 24 Oct. 2019, and 2 Nov. 2019. At each timing, 2,4-D plus glyphosate was applied over the plastic mulch using a $\mathrm{CO}_{2}$-pressurized backpack sprayer calibrated to deliver $140 \mathrm{~L} \cdot \mathrm{ha}^{-1}$. Experiments in 2018 used AIXR 11002 nozzles (Teejet Technologies, Wheaton, IL); during 2019 experiments, TTI 110015 nozzles (Teejet Technologies) were used because of changes in the Embed Extra labeling. The spray boom was $138 \mathrm{~cm}$ long with a nozzle spacing of $46 \mathrm{~cm}$; it was held 41 $\mathrm{cm}$ above the plastic mulch. At application, the air temperature was 6 to $28^{\circ} \mathrm{C}$, relative humidity was $70 \%$ to $87 \%$, and wind speeds did not exceed $5 \mathrm{~km} \cdot \mathrm{h}^{-1}$. Rainfall accumulation, solar thermal radiation, and daily maximum and minimum temperature data were collected onsite at a University of Georgia Weather Monitoring Network station (Table 1) (Knox, 2019).

Analytical methods. To quantify the removal of 2,4-D and glyphosate from plastic mulch, plastic samples were collected for analysis. Samples were taken within $2 \mathrm{~h}$ after each treatment and at the time of planting for two samples per treated plot. Samples collected $2 \mathrm{~h}$ after application were the $0 \mathrm{~d}$ after application (DAA) samples; the at-planting samples were collected $1,15,30$, and 45 DAA. Sampling methods were similar to those used during previous studies (Grey et al., 2009, 2018). Samples of plastic mulch were collected from each plot using an openfaced wooden square frame with an inside area of $0.1 \mathrm{~m}^{2}$. A box-cutting knife was used to cut the plastic mulch along the inside edge of the square. Then, needle-nose pliers were used to mechanically fold the plastic mulch inward without contacting the treated side of the plastic mulch, thus preventing contact of the treated surface with any foreign objects. Samples were placed in plastic bags and stored at $-10^{\circ} \mathrm{C}$ until analysis.

Field plot replicate sample integrity was maintained throughout sample collection, preparation, and chemical analysis. For the herbicide analysis, samples were removed from the freezer and allowed to equilibrate to room temperature before being placed in a $125-\mathrm{mL}$ volumetric flask sealed with a rubber stopper. Extractions were conducted using a 1:10 ratio of methanol and highperformance liquid chromatography water (Fisher Scientific International, Hampton, $\mathrm{NH})$. The extraction volumes were $100 \mathrm{~mL}$, with plastic samples placed on a reciprocating shaker for $2 \mathrm{~h}$ at $200 \mathrm{rpm}$. Upon removal, liquid samples were passed through a $0.2-\mu \mathrm{M}$ polytetrafluoroethylene membrane filter (Fisher Scientific International) that was fitted to a Luer-Lok ${ }^{\mathrm{TM}}$ syringe (Fisher Scientific International) and then passed into a $1.5-\mathrm{mL}$ microcentrifuge tube (Fisher Scientific International). Microcentrifuge tubes were sealed and centrifuged at 12,000 rpm for $5 \mathrm{~min}$. Then, an aliquot of $1000 \mu \mathrm{L}$ was transferred to injection vials (Fisher Scientific International). Samples were analyzed with a Waters Acquity Arc ultrahigh-performance liquid chromatography 
Table 1. Environmental data for 2,4-D choline plus glyphosate removal from plastic mulch.

\begin{tabular}{|c|c|c|c|c|c|c|c|c|c|c|c|c|}
\hline \multirow[b]{3}{*}{ Treatment } & \multicolumn{4}{|c|}{2018} & \multicolumn{4}{|c|}{ 2019-PD 1} & \multicolumn{4}{|c|}{ 2019-PD 2} \\
\hline & \multicolumn{2}{|c|}{ Temperature $^{z}$} & \multirow{2}{*}{$\begin{array}{c}\text { Rainfall }^{\mathrm{y}} \\
\mathrm{cm}\end{array}$} & \multirow{2}{*}{$\begin{array}{c}\text { Radiation }^{\mathrm{x}} \\
\mathrm{MJ} \cdot \mathrm{m}^{-2}\end{array}$} & \multicolumn{2}{|c|}{ Temperature } & \multirow{2}{*}{$\begin{array}{l}\text { Rainfall } \\
\mathrm{cm}\end{array}$} & \multirow{2}{*}{$\begin{array}{c}\text { Radiation } \\
\mathrm{MJ} \cdot \mathrm{m}^{-2}\end{array}$} & \multicolumn{2}{|c|}{ Temperature } & \multirow{2}{*}{$\begin{array}{c}\text { Rainfall } \\
\mathrm{cm}\end{array}$} & \multirow{2}{*}{$\begin{array}{c}\text { Radiation } \\
\mathrm{MJ} \cdot \mathrm{m}^{-2}\end{array}$} \\
\hline & Max & Min & & & Max & Min & & & Max & Min & & \\
\hline 45 DBP & 31.0 & 19.4 & 9.6 & 770 & 30.8 & 18.0 & 7.3 & 753 & 29.1 & 16.3 & 10.2 & 693 \\
\hline $30 \mathrm{DBP}$ & 29.6 & 18.1 & 9.6 & 438 & 29.8 & 17.1 & 7.3 & 467 & 26.9 & 15.0 & 10.2 & 403 \\
\hline $15 \mathrm{DBP}$ & 27.1 & 15.0 & 0.5 & 186 & 26.3 & 14.7 & 6.6 & 217 & 24.6 & 12.5 & 5.2 & 201 \\
\hline $1 \mathrm{DBP}$ & 19.8 & 12.4 & 0.5 & 7 & 24.2 & 9.7 & 0.5 & 10 & 19.4 & 5.00 & 0.5 & 16 \\
\hline
\end{tabular}

${ }^{\mathrm{z}}$ Average daily maximum and minimum after application and before planting reported as ${ }^{\circ}$ Celsius.

${ }^{\mathrm{y}}$ Total rainfall or overhead irrigation after application and before planting. Overhead irrigation at $1 \mathrm{DBP}$ was applied $\approx 6 \mathrm{~h}$ after the herbicide application at 1 DBP.

${ }^{\mathrm{x}}$ Sum of total solar radiation after application and before planting.

$\mathrm{DBP}=$ days before planting; $\mathrm{PD}=$ planting date.

system coupled with a Waters 2998 PDA and Waters QDa Mass Spectrometry Detector (Waters Corporation, Milford, MA).

For analysis of 2,4-D, the mobile phase consisted of 1:9 acetonitrile:water, 9:1 acetonitrile:water, and water. A Cortecs $\mathrm{C}_{18} 4.6-\times$ 50-mm column with $2.7-\mu \mathrm{m}$ packing (Waters Corporation) with a flow rate of 1.1 $\mathrm{mL} \cdot \mathrm{min}^{-1}$, an injection volume of $47 \mu \mathrm{L}$, and a run time of 5 min per injection was used. Chromatographic conditions were adapted from Majzik et al., (2006). For glyphosate analysis, the mobile phase consisted of water with $0.9 \%$ formic acid and acetonitrile with $0.9 \%$ formic acid. An anionic polar pesticide $2.1-\times 100-\mathrm{mm}$ column with $5-\mu \mathrm{m}$ packing (Waters Corporation) with a flow rate of 0.75 $\mathrm{mL} \cdot \mathrm{min}^{-1}$, an injection volume of $10 \mu \mathrm{L}$, and a run time of 4 min per injection was used. Standard curves were generated using the formulations applied during studies and based on the acid equivalent applied.

Crop establishment and data collection. Transplant holes were hand-punched in the plastic mulch using a custom-made stainless aluminum hole puncher on 25 Oct. 2018, 25 Oct. 2019, and 4 Nov. 2019. The custom hole punchers were used to eliminate plot-to-plot herbicide contamination. After use on each plot, the implement was cleaned with a mixture of ammonia and water before beginning the next plot. The size of the plant hole created by the custom hole punchers was identical to that of a hole created by a standard transplant hole punch wheel (Kennco Manufacturing, Inc., Ruskin, FL). 'Emerald crown' broccoli and 'Top bunch' collard (height, $10 \mathrm{~cm}$ ) were transplanted on the same day as when hole punching was performed for each location. Two rows of each crop were planted on each bed with $30-\mathrm{cm}$ in-row and betweenrow spacing. At 1 to $2 \mathrm{~d}$ after transplanting, all plots received $0.5 \mathrm{~cm}$ of irrigation to set the transplants and simulate a rainfall event whereby the herbicide could move onto the foliage of the transplants or wash into the transplant hole. Both crops were managed for irrigation, fertility, and other pests according to University of Georgia Cooperative Extension Service recommendations (Coolong et al., 2016; Coolong, 2017).

Visual crop injury (chlorosis, epinasty, stunting, leaf deformations) was rated on a scale of $0 \%$ to $100 \%(0 \%$, no injury; $100 \%$, crop death) every $7 \mathrm{~d}$ beginning 1 week after planting; this continued for 5 weeks. Reductions in broccoli and collard growth were quantified by measuring the diameter of the foliage of at least 10 plants weekly for 5 weeks after planting. Early-season fresh weight biomass was measured by removing eight plants per plot at the ground level and recording their collective weight. Ten plants per plot remained for harvest data. Broccoli were harvested five times, and the number of heads and weight per plot were recorded for each harvest. Then, harvests were split into early harvests (harvest 1 and harvest 2) and total harvests (harvests $1-5$ ) to determine the impacts of crop damage on the earliness of harvest as well as season harvest totals. Broccoli head numbers for total harvests were the same for each treatment because one head was harvested per plant. Collards were harvested three times, with the number of leaves and weight per plot recorded for each harvest. Then, collard harvests were split into the early harvest (first harvest) and total harvests (harvests 1-3) to determine the impact of crop damage on the earliness of harvest as well as the harvest throughout the season.

Statistical analysis. For analytical data, an analysis of variance (ANOVA) was performed to evaluate the experimental run $x$ treatment interactions. A regression analysis was performed using SAS nonlinear regression to determine if 2,4-D and glyphosate dissipation on plastic mulch could be described using Eq. [1] for exponential decay.

$$
y=B_{0} e^{-B_{1}(x)}
$$

In this equation, $y$ is the herbicide concentration, $B_{0}$ is the initial concentration, $B_{I}$ is the dissipation rate, and $x$ is the time in DAA. After data were regressed against time, the output from the analysis included the first-order dissipation rate constants $(k)$ (Ohmes et al., 2000). Data for the exponential decay equations were subjected to an ANOVA using the general linear models procedure with mean separation using 95\% asymptotic confidence intervals. Data were then graphed in Sigmaplot 14 (Systat Software, San Jose, CA). Additionally, PROC GLIMMIX was used to compare means of herbicide concentrations in SAS (version 9.4; SAS Institute Inc., Cary, NC). Replications and experimental runs were set as random variables. Concentration means were compared and adjusted using the Shaffer-simulated method ( $\alpha=0.05)$.

Bioassay data were subjected to an ANOVA using PROC GLIMMIX in SAS (version 9.4; SAS Institute Inc.) to determine if the combined treatment effects of rate and application timing influenced broccoli and collard growth, development, and yield. The interaction between experimental run $\times$ treatment was evaluated and determined to be not significant; therefore, all bioassay data are combined across experimental runs. Injury, crop width, biomass, and yield were set as the fixed effects, whereas experimental run and replication were considered random effects. All $P$ values for tests of differences between least-squares means were compared and adjusted using the Shaffer-simulated method ( $\alpha=0.05)$. Linear regression was attempted for bioassay response variables; however, because of the lack of fit, only the means are presented.

\section{Results and Discussion}

Analytical analysis. Interactions between experimental run $\times$ treatment were evaluated and determined to be not significant. Therefore, analytical data were combined over experimental runs. The initial concentrations of the 1065 and $2130 \mathrm{~g}$ ae/ha rates of 2,4-D, and of the 1125 and $2250 \mathrm{~g}$ ae/ha rates of glyphosate present on plastic mulch, with their respective SE, were $1282( \pm 25), 1936( \pm 35)$, $1303( \pm 54)$, and $3498( \pm 128) \mathrm{ppm} / \mathrm{m}^{2}$, respectively. Glyphosate was not detected in any samples taken at crop planting following irrigation, regardless of the rate applied (data not shown). Previous studies have demonstrated that glyphosate can be removed from plastic mulch with a single irrigation event of $1 \mathrm{~cm}$, and glyphosate is currently labeled for use over plastic mulch before vegetable transplanting (Bayer CropScience, 2018; Culpepper et al., 2009; Grey et al., 2009). The exponential decay equation accurately described removal of 2,4-D from plastic mulch with first-order rate constants $(k)$ and $95 \%$ asymptotic confidence intervals of $4.59( \pm 5.3)$ for the $1 \times$ rate of $2,4-\mathrm{D}$ and $4.83( \pm 6.4)$ for the $2 \times$ rate of 2,4-D (Fig. 1). First-order rate constants were similar for both rates of 2,4-D (data not shown). Irrigation washed, on average, $99 \%$ of the 2,4-D from the plastic mulch on the afternoon of application (Fig. 1). 


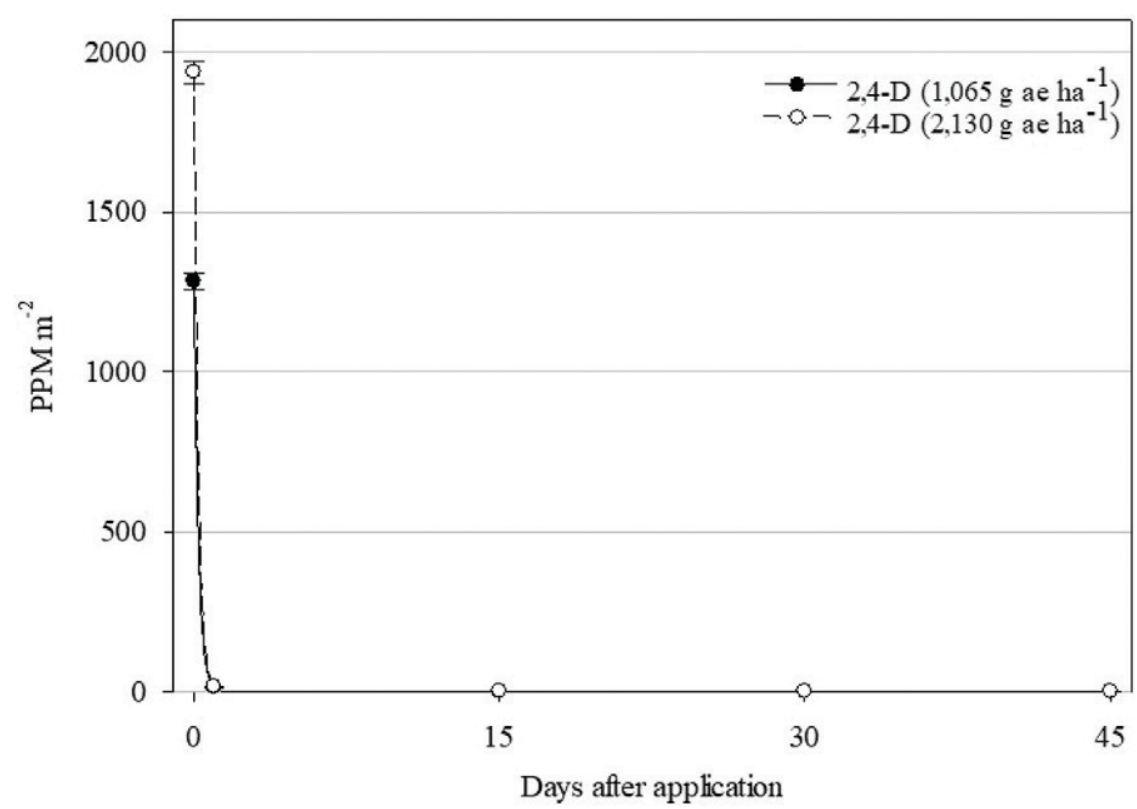

Fig. 1. The 2,4-D removal from the surface of plastic mulch using 0.5 -cm overhead irrigation $1 \mathrm{~d}$ after application (DAA) and additional time/rainfall in Georgia using the exponential decay equation $\left(y=B_{0} \mathrm{e}^{-B 1(\mathrm{x})}\right)$. Nonlinear regression was applied for DAA. The lines represent the first-order regression equation for each rate applied. Data are averaged over three experimental runs. Data points are the means of replications with bars indicating the SEM:

2,4-D (1065 g ae/ha): $\mathrm{y}=1281.9 e^{(4.5886 \mathrm{x})} ; P<0.0001 ; R^{2}=0.97$

$2,4-\mathrm{D}\left(2130 \mathrm{~g}\right.$ ae/ha): $\mathrm{y}=1936.2 e^{(4.8285 \mathrm{x})} ; P<0.0001 ; R^{2}=0.97$.

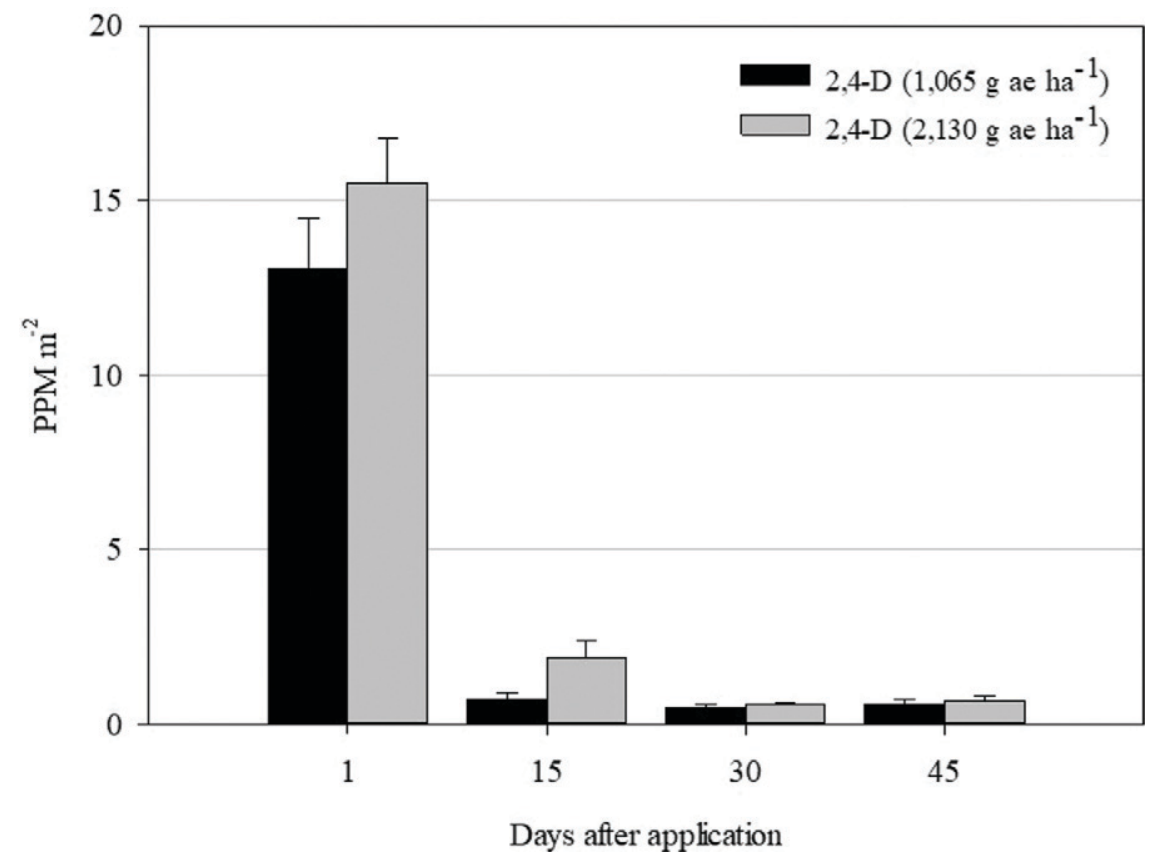

Fig. 2. The 2,4-D concentrations remaining on the surface of plastic mulch at crop transplanting as influenced by the rate applied, interval between application and planting, and environmental conditions. Data averaged over three experimental runs.

When concentrations present at application are removed from the graph, a better understanding of herbicide removal with time and additional rainfall can be observed for the applications at 1 to 45 DBP. When 2,4-D was applied and washed from the plastic mulch on the afternoon of application, concentrations at planting were 12.9 and $15.4 \mathrm{ppm} / \mathrm{m}^{2}$ for the
$1 \times$ and $2 \times$ rates, respectively (Fig. 2). Including an additional $14 \mathrm{~d}$ before planting with 0 to $6.1 \mathrm{~cm}$ of additional rainfall, concentrations were further reduced $88 \%$ to $95 \%$. Concentrations at planting for applications made at 45, 30, and 15 DBP were similar (Fig. 2). Although a single irrigation event did not completely remove 2,4-D from the surface of plastic mulch, additional time and rainfall between application and planting resulted in further concentration reductions. For example, a $1 / 100$ concentration of the 2,4-D applied was present after the irrigation on day 1; however, by day 15 , only $1 / 1000$ of the original concentration remained. Irrigation and rainfall had the greatest influence on removal of 2,4-D and glyphosate from plastic mulch; however, the application interval before planting could also have a role in reducing the risk of injury to sensitive crops in response to preplant applications of 2,4-D. Previous research has indicated that 2,4-D is not readily photodegraded, but it has demonstrated high levels of water solubility (Shaner, 2014).

For cole crops and leafy greens, the rate of 2,4-D required to visually detect symptomology often must be higher than a field use rate of $1 / 100$, even when applied directly to the foliage (Culpepper and Vance, 2019; Mohseni-Moghadam and Doohan, 2015). Therefore, crop damage should be minimal from 2,4-D applied preplant over mulch regardless of the plant-back interval or rate applied as long as $0.5 \mathrm{~cm}$ or more of overhead irrigation or rainfall is received before crop planting.

Broccoli response. Response variables measured for broccoli were not significantly impacted by the experimental run and were combined for analyses. Visual injury estimates are reported from 21 to $33 \mathrm{DAP}$, when injury was at its maximum. Broccoli injury was not impacted by the 2,4 -D plus glyphosate rate or application timing $(P=0.6465)$. Injury observed in broccoli was $\leq 7 \%$ for all treatments (Table 2). Herbicide labels for vegetable crops are highly dependent on the level of injury to the crop, with anything more than $10 \%$ often being unacceptable (Culpepper et al., 2009). These data demonstrate sufficient crop safety when 2,4-D plus glyphosate are applied preplant over plastic mulch and washed off with rainfall or irrigation before broccoli planting. Mohseni-Moghadam and Doohan (2015) also reported broccoli was tolerant to low levels of 2,4-D, with injury of only $10 \%$ to $16 \%$ when applying a $1 / 50$ to $1 / 100$ field rate. Similarly, when canola foliage was treated with a $1 / 25$ field rate of 2,4-D or less, the observed injury was $\leq 5 \%$ (Wall, 1996).

Broccoli widths at 27 to 31 DAP were not influenced by the rate of herbicides applied or application timing $(P=0.5036)$. Broccoli in the control had an average width of $33.6 \mathrm{~cm}$, with no differences observed among treatments (Table 2). Fresh weight biomass, collected 26 to 35 DAP, followed similar trends because 2,4-D treatments did not influence weights when compared with the control $(P=0.3675)$.

The earliness of harvest is important for vegetable production because it can have a tremendous impact on the fruit value (Culpepper et al., 2018). Herbicide injury has the potential to delay the maturity of vegetable crops, which can lead to economic losses. In an attempt to quantify the potential delay in maturity caused by treatments, head count and weight data from the first two harvests 
Table 2. Broccoli response to 2,4-D choline plus glyphosate applied over plastic mulch followed by $0.5 \mathrm{~cm}$ overhead irrigation before transplanting. ${ }^{2}$

\begin{tabular}{|c|c|c|c|c|c|c|c|}
\hline \multirow[b]{2}{*}{ Rate $^{\mathrm{y}}$} & \multirow[b]{2}{*}{$\begin{array}{l}\text { Application timing } \\
\text { DBP }\end{array}$} & \multirow[b]{2}{*}{$\begin{array}{c}\text { Injury }^{x} \\
\%\end{array}$} & \multirow[b]{2}{*}{$\begin{array}{c}\text { Width }^{\mathrm{x}} \\
\mathrm{cm}\end{array}$} & \multirow[b]{2}{*}{$\begin{array}{c}\text { Biomass }^{\mathrm{x}} \\
\text { g/plant }\end{array}$} & \multicolumn{2}{|c|}{ Harvests 1 and 2} & \multirow{2}{*}{$\begin{array}{c}\text { Harvests 1-5 } \\
\begin{array}{c}\text { Head } \mathrm{wt}^{\mathrm{x}} \\
\mathrm{kg} \cdot \mathrm{ha}^{-1}\end{array}\end{array}$} \\
\hline & & & & & $\begin{array}{c}\text { Broccoli headsw } \\
\text { no./ha }\end{array}$ & $\begin{array}{l}\text { Head wt }^{\mathrm{x}} \\
\mathrm{kg} \cdot \mathrm{ha}^{-1}\end{array}$ & \\
\hline \multirow[t]{3}{*}{$1065+1125 \mathrm{~g}$ ae/ha } & 45 & $5 \mathrm{NS}$ & $31.9 \mathrm{NS}$ & $60.8 \mathrm{NS}$ & $26,360 \mathrm{NS}$ & $11,890 \mathrm{NS}$ & $22,204 \mathrm{NS}$ \\
\hline & 15 & 4 & 32.9 & 65.6 & 30,035 & 13,745 & 22,878 \\
\hline & 1 & 4 & 32.7 & 65.6 & 27,557 & 12,927 & 23,644 \\
\hline \multirow[t]{2}{*}{$2130+2250 \mathrm{~g}$ ae/ha } & 45 & 5 & 32.3 & 63.4 & 25,159 & 11,266 & 22,270 \\
\hline & 1 & 4 & 32.6 & 64.9 & 26,777 & 12,001 & 23,881 \\
\hline NTC & & 0 & 33.6 & 65.6 & 30,751 & 13,507 & 22,249 \\
\hline
\end{tabular}

${ }^{\mathrm{z}}$ All data are averaged over three experimental runs.

${ }^{\mathrm{y}}$ Rates correspond to 2,4-D choline + glyphosate.

${ }^{\mathrm{x}}$ Means were compared within columns and did not differ from those of the nontreated control according to the Shaffer-simulated test $(\alpha=0.05)$.

$\mathrm{DBP}=$ days before planting; $\mathrm{Ns}=$ not significant; NTC $=$ nontreated control.

Table 3. Collard response to 2,4-D choline plus glyphosate applied over plastic mulch followed by $0.5 \mathrm{~cm}$ of overhead irrigation before transplanting. ${ }^{2}$

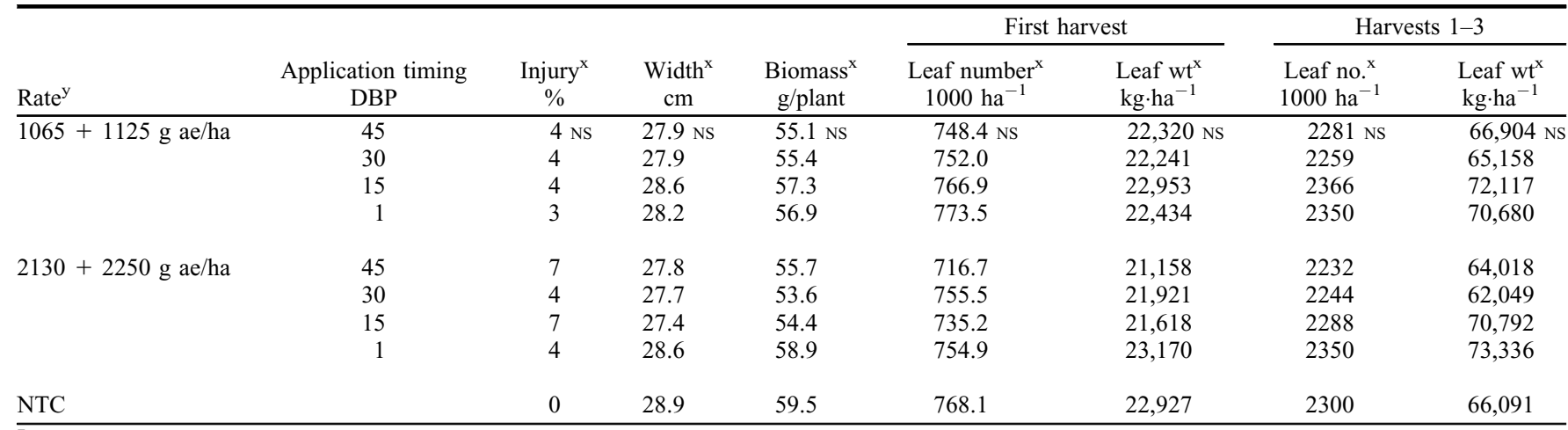

${ }^{\mathrm{z}}$ All data are averaged over three experimental runs.

${ }^{\mathrm{y}}$ Rates correspond to 2,4-D choline + glyphosate.

${ }^{\mathrm{x}}$ Means were compared and did not differ from those of the nontreated control according to the Shaffer-simulated test $(\alpha=0.05)$.

$\mathrm{DBP}=$ days before planting; $\mathrm{NS}=$ not significant; NTC $=$ nontreated control.

were summarized. Early-season broccoli head counts and weight were not impacted by the rate applied or application timing $(P=$ 0.9043 and $P=0.9858$, respectively). Broccoli in the control plots yielded an average of 30,751 heads/ha weighing $13,507 \mathrm{~kg} \cdot \mathrm{ha}^{-1}$, with no differences among treatments (Table 2). Similarly, treatments did not influence the season-long harvested broccoli head number $(P=0.9998)$ or weight $(P=0.9935)$. Over the entire season, broccoli in the nontreated plots had an average of 71,729 heads/ha weighing $21,623 \mathrm{~kg} \cdot \mathrm{ha}^{-1}$.

Collard response. Response variables measured for collards were not significantly impacted by the experimental run and were combined for analyses. Visual injury estimates were at their maximum at 21 to 30 DAP. Collard injury was not influenced by the rate applied or application timing $(P=$ 0.4783 ). Collard injury was $\leq 7 \%$ among treatments, with the results being similar to those noted for broccoli.

Collards in the control plots had an average width of $28.9 \mathrm{~cm}$ at 27 to 31 DAP (Table 3 ). Widths of collards in treated plots at this time ranged from 27.4 to $28.6 \mathrm{~cm}$ and were similar to those of the control. Similarly, 2,4-
D plus glyphosate treatments did not influence collard biomass. Fresh weight biomass was collected at 26 to $35 \mathrm{DAP}$, with the control weighing $59.5 \mathrm{~g} /$ plant (Table 3 ).

With respect to early-season collard yield, there were no differences in leaf number $(P=$ $0.9976)$ or weight $(P=0.9989)$; collards in the control yielded 768,100 leaves/ha and weighed $22,927 \mathrm{~kg} \cdot \mathrm{ha}^{-1}$ (Table 3). A similar trend was noted for yield over the entire season for both leaf number $(P=0.9873)$ and weight $(P=0.7512)$; collards in the control yielded 2,300,000 leaves/ha weighing $66,091 \mathrm{~kg} \cdot \mathrm{ha}^{-1}$ over the entire season. Differences in collard leaf number with any treatment were less than $3 \%$ when compared with the control.

2,4-D could be a useful tool for vegetable producers attempting to control problematic weeds before planting. Preplant applications of 2,4-D tank-mixed with glyphosate resulted in $\leq 7 \%$ crop injury without influencing crop growth, biomass, early season yield, or total yield for broccoli and collards as long the plastic mulch was washed with $0.5 \mathrm{~cm}$ of irrigation before planting. Additionally, these studies demonstrated no differences between the $1 \times$ and $2 \times$ use rates for all response variables for each crop. Of note, these studies were conducted with no holes in the plastic mulch at the time of application. The presence of holes in the plastic mulch can complicate weed management in multicropped plastic because of the potential for residual herbicide uptake by crops planted after application. Therefore, future research should evaluate the optimal plant-back interval of vegetable crops planted in multicropped plastic mulch with holes that have been treated with 2,4-D.

\section{Literature Cited}

Bayer CropScience. 2018. Roundup Powermax ${ }^{\circledR}$ herbicide product label. Publication no. 101816. St. Louis, MO.

Bitterlich, I., M.K. Upadhyaya, and S.I. Shibairo. 1996. Weed control in cole crops and onion (Allium cepa) using ammonium nitrate. Weed Sci. 44:952-958.

Brainard, D.C., R.E. Peachey, E.R. Haramoto, J.M. Luna, and A. Rangarajan. 2013. Weed ecology and nonchemical management under strip-tillage: Implications for northern U.S. vegetable cropping systems. Weed Technol. 27:218-230.

Chase, C.A., T.A. Bewick, and D.G. Shilling. 1998. Characterization of paraquat resistance in Solanum americanum Mill. II. Evidence for a chloroplast mechanism. Pestic. Biochem. Physiol. 60:23-30. 
Chaudhari, S., D.L. Jordan, A.C. York, K.M. Jennings, C.W. Cahoon, A. Chandi, and M.D. Inman. 2017. Biology and management of glyphosate-resistant and glyphosate-susceptible Palmer amaranth (Amaranthus palmeri) phenotypes from a segregating population. Weed Sci. 65:755-768.

Coolong, T. 2017. Commercial production and management of cabbage and leafy greens. Bul. 1181. University of Georgia, Athens, GA.

Coolong, T., A. Sparks, and B. Dutta. 2016. Fresh market broccoli production for Georgia. Bul. 1460. University of Georgia, Athens, GA.

Corteva. 2018. Enlist ${ }^{\mathrm{TM}}$ Duo with Colex D technology herbicide product label. Dow AgroSciences publication no. D02-407-003. Indianapolis, IN.

Csinos, A.S., W.C. Johnson, A.W. Johnson, D.R Sumner, R.M. McPherson, and R.D. Gitaitis. 1997. Alternative fumigants for methyl bromide in tobacco and pepper transplant production. Crop Prot. 16:585-594.

Culpepper, A.S., D.S. Carlson, and A.C. York. 2005. Pre-plant control of cutleaf eveningprimrose and wild radish in conservation tillage cotton. J. Cotton Sci. 9:223-228.

Culpepper, A.S., T.L. Grey, and T.M. Webster. 2009. Vegetable response to herbicides applied to low-density polyethylene mulch prior to transplant. Weed Technol. 23:444-449.

Culpepper, A.S., T.L. Grey, W.K. Vencill, J.M. Kichler, T.M. Webster, S.M. Brown, A.C. York, J.W. Davis, and W.W. Hanna. 2006. Glyphosate-resistant Palmer amaranth (Amaranthus palmeri) confirmed in Georgia. Weed Sci. 54:620-626.

Culpepper, A.S., L.M. Sosnoskie, J. Shugart, N. Leifheit, M. Curry, and T. Gray. 2018. Effects of low-dose applications of 2,4-D and dicamba on watermelon. Weed Technol. 32:267-272.

Culpepper, A.S. and J.C. Vance. 2019. Palmer amaranth control in Georgia cotton during 2019. Cir. 952. University of Georgia, Athens, GA.
Culpepper, A.S., J.C. Vance, and B. Dutta. 2017. 2017 Vegetable fumigant systems for plasticulture for Georgia. Bul. 1068. University of Georgia, Athens, GA.

Cutulle, M., H. Campbell, D.M. Couillard, B. Ward, and M.W. Farnham. 2019. Pre transplant herbicide application and cultivation to manage weeds in southeastern broccoli production. J. Crop Prot, doi: 10.1016/j.croppro.2019.104862.

Eure, P.M. and A.S. Culpepper. 2017. Bell pepper and weed response to dimethyl disulfide plus chloropicrin and herbicide systems. Weed Technol. 31:694-700.

Grey, T.L., W.K. Vencill, T.M. Webster, and A.S. Culpepper. 2009. Herbicide dissipation from low density polyethylene mulch. Weed Sci. 57: 351-356.

Grey, T.L., A.S. Culpepper, X. Li, and W.K. Vencill. 2018. Halosulfuron-methyl degradation from the surface of low-density polyethylene mulch using analytical and bioassay techniques. Weed Sci. 66:15-24.

Hydrick, D.E. and D.R. Shaw. 1995. Non-selective and selective herbicide combinations in stale seedbed (Glycine max). Weed Technol. 9:158-165.

Kemble, J.M., I.M. Meadows, K.M. Jennings, and J.F. Walgenbach (eds.). 2019. 2019 Vegetable crop handbook. Southeastern Vegetable Extension Workers, Auburn, AL.

Knox, P. 2019. Georgia automated environmental monitoring network. University of Georgia, Griffin, GA. 8 Nov. 2019. <https://www. georgiaweather.net/ $>$.

Leon, R.G., J.A. Ferrell, and B.A. Sellers. 2016. Seed production and control of sicklepod (Senna obtusifolia) and pitted morningglory (Ipomoea lacunosa) with 2,4-D, dicamba, and glyphosate combinations. Weed Technol. 30:76-84.

Majzik, E.S., F. Toth, L. Benke, and Z. Kiss. 2006. SPE-LC-MS-MS Determination of Phenoxy Acid Herbicides in Surface and Ground Water. Chromatographia 63:S105-S109.
Mohseni-Moghadam, M. and D. Doohan. 2015. Response of bell pepper and broccoli to simulated drift rates of 2,4-D and dicamba. Weed Technol. 29:226-232.

Moretti, M.L. and B.D. Hanson. 2016. Reduced translocation is involved in resistance to glyphosate and paraquat in Conyza bonariensis and Conyza canadensis from California. Weed Res. 57:25-34.

Ohmes, G.A., T.C. Mueller, and R.M. Hayes. 2000. Sulfentrazone dissipation in a Tennessee soil. Weed Technol. 14:100-105.

Randell, T.M., J.C. Vance, and A.S. Culpepper. 2020. Broccoli, cabbage, squash and watermelon response to halosulfuron preplant over plastic mulch. Weed Technol. 34:202-207.

Shaner, D.L. (ed.). 2014. Herbicide handbook. Weed Science Society of America, Lawrence, KS.

Smart, J.R., L. Brandenberger, and D. Makus. 2001. Cabbage (Brassica oleracea L.) response to sulfentrazone for broadleaf weed control. J. Veg. Crop. Prod. 7:97-108.

Sosnoskie, L.M., A.S. Culpepper, L.B. Braxton, and J.S. Richburg. 2015. Evaluating the volatility of three formulations of 2,4-D when applied in the field. Weed Technol. 29:177-184.

U.S. Department of Agriculture. 2019. National Agricultural Statistics Service. 14 Aug. 2020. $<$ http://nass.usda.gov/index.php/ $>$.

Wall, D.A. 1996. Effect of sublethal dosages of 2,4-D on annual broadleaf crops. Can. J. Plant Sci. 76:179-185.

Webster, T.M., A.S. Csinos, A.W. Johnson, C.C. Dowler, D.R. Sumner, and R.L. Fery. 2001. Methyl bromide alternatives in a bell pepper squash rotation. Crop Prot. 20:605-614.

Webster, T.M. 2014. Weed survey-southern states: Vegetable, fruit and nut crops subsection, p. 282-293. In: Proceedings of the Southern Weed Science Society. Southern Weed Science Society, Birmingham, AL. 